Klinik Araştırma/Clinical Research

\title{
Multipl skleroz hastalarında cinsel fonksiyon bozukluğu
}

\author{
Sexual dysfunction in multiple sclerosis patients \\ Murat Terzi ${ }^{*} a$, Birsen Kocamanoğlu ${ }^{b}$, Hatice Güz $^{b}$, Musa Onar $^{a}$, Ahmet Rıfat Şahin ${ }^{b}$ \\ a Ondokuz Mayıs Üniversitesi Tip Fakültesi Nöroloji AD., Samsun

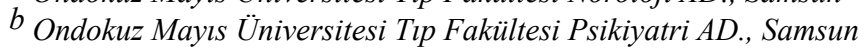

\begin{tabular}{l}
\hline MAKALE BÍLGÍLERİ \\
\hline Makale Geçmişi: \\
\begin{tabular}{ll} 
Geliş & $13 / 11 / 2008$ \\
Kabul & $15 / 03 / 2010$ \\
\hline
\end{tabular}
\end{tabular}

\section{*Yazışma Adresi}

Murat TERZİ

Ondokuz Mayıs Üniversitesi

Tıp Fakültesi Nöroloji Anabilim Dalı

55139 Kurupelit, SAMSUN

E-posta: mterzi@omu.edu.tr

\section{Anahtar Kelimeler: \\ Multipl Skleroz \\ Seksüel Disfonksiyon \\ Dizabilite \\ Psikiyatrik Semptomlar \\ Yaşam Kalitesi \\ Tedavi}

\section{Key Words :}

Multiple Sclerosis

Sexual Dysfunction

Dysability

Psychiatric Symptoms

Life Quality

Treatment

\section{ÖZET}

Amaç: Multipl skleroz (MS), genellikle genç erişkin yaşlarda başlayan, otoimmün, inflamatuvar, demyelinizan bir hastalıktır. MS hastalarında, organik rahatsızlıklara birçok ruhsal ve sosyal sorunun da eşlik ettiği görülmektedir. Bu çalışmada sıklıkla genç erişkin yaşlarda görülen ve kronik bir hastalık olan MS hastalarında bilinen bir psikiyatrik problem veya ileri derecede özürlülük olmaksızın olası cinsel işlev bozukluğu sıklığını saptamak amaçlanmıştır.

Yöntem: Çalışmaya Mc Donald kriterlerine göre kesin MS tanısı almış, "relapsing remitting" klinik formda olan 56 hasta alındı. Tüm hastalara olası cinsel işlev bozukluğunu saptamaya yönelik Arizona Cinsel Yaşantılar Ölçeği (ACYÖ) uygulandı.

Bulgular: Hastaların ortalama yaşı $35.07 \pm 8.72$ yıl $(\mathrm{min}=21$, $\max =46)$ idi. Hastaların 34 'ü (\%60. 7) kadın, 22'si (\%39. 3) erkekti. Kadın cinsiyetin ortalama Genişletilmiş Özürlülük Durum Skalasi (EDSS) 2.29 \pm 1.45 , erkek cinsiyetin ortalama EDSS'si $2.45 \pm 1.68$ 'di. Ortalama hastalık süresi $6.14 \pm 3.14$ yıldı. Kadın cinsiyette ortalama ACYÖ $16.26 \pm 5.12$,

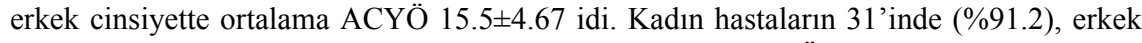
hastaların 19'unda (\%86.4) cinsel işlev bozukluğu vardı. ACYÖ ile hastalık süresi, EDSS arasında istatistiksel anlamlı ilişki yoktu ( $\mathrm{p}>0.05)$.

Sonuç: Hastalarımızda cinsel işlevleri etkileyebilecek ölçüde hastalığa bağlı özürlülük, psikiyatrik bir problem veya ilaç kullanım öyküsü olmamasına rağmen, çoğunda cinsel işlev bozukluğu olduğu belirlendi. Cinsel işlev bozukluğuna neden olabilecek bilinen bir risk faktörü olmamasına rağmen cinsel işlev bozukluğunun görülebilmesi, hastalığın nöral enformasyon ve santral sinir sistemi üzerine olan etkisi ile açılanabilir.

J. Exp. Clin. Med., 2009; 26:81-85

\section{ABSTRACT}

Objective: Multiple sclerosis (MS) is an autoimmune, inflammatory, demyelinisan disease which onsets at young adult ages. In MS patients, a lot of psychological and social problem are observed along with the organic problems. The aim of this work is detecting the frequency of the sexual function disorder developed in the MS patients without any known psychiatric problem and/or advanced disability.

Methods: 56 patients, who were diagnosed as MS "relapsing remitting clinical form" according to the Mc Donald criteria, participated in this study. Sexual functions of the patients were measured by the "Arizona Sexual" Experience Scale (ASEX).

Results: The Mean SD age of the 56 subjects ( 34 women, 22 men) was $35.07 \pm 8.72$ years $(\min =21, \max =46)$. The average Expanded Disability Status Scala (EDSS) score of the women was $2.29 \pm 1.45$, while the EDSS score for the men was $2.45 \pm 1.68$. The average disease duration was $6.14 \pm 3.14$ years. The average ASEX score for the women was 16.26 \pm 5.12. The average ASEX score for the men was 15. $5 \pm 4.67 .31(91.2 \%)$ of the women and $19(86.4 \%)$ of the men had ASEX scores above 11 . There was no statistical relationship observed between the ASEX score, the disease duration and EDSS score. The average EDSS score of the subjects was $2.35 \pm 1.53$ and the patients have no sexual disabilities that affect /sexual/ functioning.

Conclusion: Additionally, the patients have no psychiatric problems or the story of drug use that can be related to a sexual function disorder. In spite of the absence of any known 
risk factors that can result a sexual function disorder, the developed sexual function disorder can be explained by the influences of the disease on the central neural system and the neural information.

J. Exp. Clin. Med., 2009; 26:81-85 C 2009 OMÜ Tüm Hakları Saklıdır.

\section{Giriş}

Multipl skleroz (MS), genellikle genç erişkin yaşlarda başlayan, kadın cinsiyette daha fazla görülen, yineleyen nörolojik fonksiyon bozukluklarıyla seyreden, otoimmün karakterde inflamatuvar demyelinizan ve/veya nörodejeneratif bir hastalıktır (Gilroy, 2000). MS gelişmiş ülkelerde genç yaş grubunda en sık görülen nörolojik özürlülük nedenidir (Confavreux ve ark., 2000). Relapsing remitting multipl skleroz (RRMS) genç hasta grubunda daha fazla görülür ve ataklarla seyreder (Miller., 2001). S1k geçirilen ataklar, uzun dönemde nörolojik fonksiyon bozukluklarını artırabilir (Paty ve ark., 1997; Gilroy, 2000). Her hastayı farklı şiddetle etkilediği için kapsamlı bir değerlendirme yapılmasında, daha önce uygulanan tedavi programları hakkında da bilgi edinip multidisipliner yaklaşımda bulunulmasında yarar vardır. MS hastalarında, organik rahatsızlıklara birçok ruhsal ve sosyal sorunun da eşlik ettiği görülmektedir. Sıklıkla belirtilen özgül stres kaynakları ekonomik ve sosyal ilişkilerin kaybı, fiziksel sağlık ve etkinlik kısıtlamaları, beden işlev kaybı ve bozulmuş beden imgesi, artmış bağımlılık ve ölüm tehlikesi, aile içinde rollerin değişmesi, iş işlevi ve ekonomik güvencede bozulma, boş vakit ve sosyal etkinliklere azalmış katılımı içermektedir (Miller, 2001; Costello ve Haris, 2003). $\mathrm{Bu}$ ağır fiziksel ve psikososyal stres etkenlerinden etkilenen hastalarda, başta depresyon ve anksiyete bozuklukları olmak üzere, ruhsal bozuklukların sık görüldüğü bildirilmektedir (Miller, 2001; Costello ve Haris, 2003).

MS hastalarında oluşan psikiyatrik sendromlar; organik ruhsal bozukluklar, duygudurum bozuklukları, kişilik ve mizaç değişiklikleri, konversif reaksiyonlar gibi birçok durum gözlenebilir. Hastalığa ilişkin yaşanan psikososyal sorunlar oldukça fazla olup çevrenin ilgisini

Tablo : 1 - Cinsel fonksiyon bozukluğu olan ve olmayan grupta sosyodemografik değişkenler

\begin{tabular}{|c|c|c|c|c|c|}
\hline & Grup I & Grup II & Toplam & $\mathrm{p}$ \\
\hline & & Sayı (\%) & Sayı (\%) & Sayı (\%) & $>0.05$ \\
\hline \multirow{2}{*}{ Cinsiyet } & Kadın & $3(8.8)$ & $31(91.2)$ & $34(100)$ & \multirow[t]{2}{*}{$>0.05$} \\
\hline & Erkek & $3(13.6)$ & $19(86.4)$ & $22(100)$ & \\
\hline \multirow{2}{*}{ Medeni durum } & Bekar & $0(0)$ & $15(100)$ & $15(100)$ & \multirow{2}{*}{$>0.05$} \\
\hline & Evli & $6(14.6)$ & $35(85.4)$ & $41(100)$ & \\
\hline \multirow{5}{*}{ Meslek } & Memur & $1(14.3)$ & $6(85.7)$ & $7(100)$ & \multirow{5}{*}{$>0.05$} \\
\hline & İşçi & $1(33.3)$ & $2(66.7)$ & $3(100)$ & \\
\hline & Serbest & $1(6.7)$ & $14(93.3)$ & $15(100)$ & \\
\hline & İşsiz & $3(12.0)$ & $22(88.0)$ & $25(100)$ & \\
\hline & Emekli & $0(0)$ & $6(100)$ & $6(100)$ & \\
\hline \multirow{3}{*}{$\begin{array}{l}\text { Sosyoekon. } \\
\text { durum }\end{array}$} & Düşük & $2(13.3)$ & $13(86.7)$ & $15(100)$ & \multirow{3}{*}{$>0.05$} \\
\hline & Orta & $4(10.5)$ & $34(89.5)$ & $38(100)$ & \\
\hline & Yüksek & $0(0)$ & $3(100)$ & $3(100)$ & \\
\hline \multirow{2}{*}{ Yaşadığı yer } & İl-ilçe & $5(11.6)$ & $38(88.4)$ & $43(100)$ & \\
\hline & Belde- Köy & $1(7.7)$ & $12(92.3)$ & $13(100)$ & \\
\hline \multirow{2}{*}{$\begin{array}{c}\text { Ailede psik } \\
\text { hastalık öyküsü }\end{array}$} & Var & $1(12.5)$ & $7(87.5)$ & $8(100)$ & \multirow[b]{2}{*}{$>0.05$} \\
\hline & Yok & $5(10.4)$ & $43(89.6)$ & $48(100)$ & \\
\hline
\end{tabular}

kaybedeceği, çevreye yük olacağı, yeterli olmadığı, reddedileceği gibi düşünceler oluşabilir. Ayrıca sfinkter denetim güçlükleri, cinsel sorunlar, kadınlarda hamilelik ve çocuk doğurmaya ilişkin endişeler oluşabilir (Özkan, 1993).

MS'li kadın ve erkeklerde cinsel işlev bozukluğu da oldukça sıktır. MS'de cinsel işlev bozukluğu primer, sekonder ve tersiyer olmak üzere üç şekilde görülebilmektedir (Costello ve Haris, 2003). MS'in genital sinirlerde meydana getirdiği hasara bağlı olarak görülenler primer, MS'in neden olduğu fiziksel değişikliklere ve ilaçların yan etkilerine bağlı gelişenler sekonder, psikososyal ve kültürel etkilere bağlı gelişen cinsel işlev bozuklukları ise tersiyer olarak adlandırılır. MS'li erkeklerde azalmış penil his nedeniyle ereksiyon sağlama ya da sürdürmede güçlük görülebilir. Erkeklerde \%40 görülen parsiyel veya komplet erektil impotans nadiren geçici olup, daha sık olarak da kalıcıdır. Her iki cinste de libido azalması olabilir. MS'li kadınlarda ise alt ekstremitede spastisite, vajinal lubrikasyon olmaması ve vajinal his azalması seklinde cinsel işlev kaybı bulguları görülür (Fraser ve ark., 2008; Kessler ve ark., 2009). MS hastalarında cinsel işlev bozuklukları başlangıç evrelerinden çok, hastalığın kronik sürecinde ortaya çıkar. Çeşitli çalışmalarda cinsel fonksiyon bozukluk oranları erkeklerde \%60-91, kadınlarda \%52-77 olarak bildirilmektedir (Baral ve ark., 1995; Fraser ve ark., 2008; Kessler ve ark., 2009). Erkeklerde en sik problem erektil disfonksiyon, kadınlarda ise orgazmik bozukluklar ve cinsel istek azalmasıdır. Erektil disfonksiyonun yaklaşık $\% 90$ '1 temelde nörolojik, sadece \%10'u psikojenik olarak değerlendirilebilir (Brown ve Haaser, 2005).

$\mathrm{Bu}$ çalışmada, sıklıkla genç erişkin yaşlarda görülen ve kronik bir hastalık olan MS hastalarında, bilinen bir psikiyatrik problem veya ileri derecede özürlülük olmaksızın, olası cinsel işlev bozukluğu sıklığını saptamak amaçlanmıştır.

\section{Araştırma Yöntemi}

Çalışmaya Ağustos 2007 - Nisan 2008 tarihleri arasında Ondokuz Mayıs Üniversitesi Tıp Fakültesi Nöroloji Anabilim Dalı MS polikliniğinde izlenen Mc Donald kriterlerine (McDonald ve ark., 2001) göre kesin MS tan1s1 almış, "relapsing remitting" klinik formda olan hastalar alındı. MS hastalarının tanısının konulması, klinik formunun belirlenmesi ve poliklinik izlemi Ondokuz Mayıs Üniversitesi Tıp Fakültesi Nöroloji Anabilim Dalı MS polikliniğinde yapıldı.

MS'li hastaların fonksiyonel durumlarını değerlendirmek için Genişletilmiş Özürlülük Durum Skalası (Expanded Disability Status Scala-EDSS) skoru (Kurtzke, 
1983) kullanıldı. Hastaların yaşı, hastalık süresi, hastalık başlangıcı ve klinik seyirde etkilenen nörolojik sistemler, nörolojik muayene bulguları, takip süreleri ve toplam atak sayıları belirlendi. EDSS'si 4.5'in üzerinde olan hastalar, daha önce bilinen cinsel işlev bozukluğu olanlar, menopoz dönemindeki kadın hastalar, düzenli partneri olmayanlar, son 2 ay içerisinde cinsel fonksiyon bozukluğuna yol açabilecek ilaç kullanımı olanlar (örn, psikotroplar, antidepresanlar), Beck depresyon ölçeği (BDÖ) 13 ve üzerinde olan hastalar ve bilinen psikiyatrik problemi olan hastalar çalışmaya alınmadı.

Tüm hastalara olası cinsel işlev bozukluğunu saptamaya yönelik Arizona Cinsel Yaşantılar Ölçeği (ACYÖ) uygulandı. Hastaların cinsel alanda yaşadıkları sorunları kısa, kolay biçimde taramak ve saptamak amacıyla McGahuey ve ark. tarafından geliştirilen bu ölçek, altılı likert tipinde değerlendirme yapmaya olanak sağlayan 5 maddeden oluşmakta ve kadın / erkek için ayrı formları bulunmaktadır (McGahuey ve ark., 2000). Yönergede son bir haftanın değerlendirilmesi istenmektedir. Ölçeğin Türkçe formunun geçerlilik ve güvenilirliği Soykan (Soykan, 2004) tarafından yapılmış olup ölçek kesim puanı 11 olarak saptanmıştır. 11 puan ve üzerinde olan kişiler cinsel fonksiyon bozukluğu bulunma riski yüksek kişiler olarak değerlendirilmektedir. Puan artışı doğrudan patolojinin şiddeti ile ilişkilidir.

Tüm hastalara olası depresyonun varlığını belirlemek için BDÖ uygulandı. BDÖ 1961'de Beck ve arkadaşları (Beck., 1961) tarafından geliştirilmiş olup Türkiye'de geçerlilik ve güvenirlilik çalışması ve Türk diline uygunluğu 1980'de Tegin (Tegin., 1980) tarafından yapılmış ve güvenirlik katsayısı 0.65 olarak bulunmuștur. Bu toplam puan depresyon belirtilerinin düzeyini veya şiddetini belirtmektedir. 0-13 puan: depresyon yok, 14-24 puan: orta derecede depresyon 25 ve üzeri puan: ciddi depresyon kabul edilmektedir.

Çalışma sonunda elde edilen veriler bilgisayar ortamında SPSS 13.0 istatistik paket programına aktarılarak analiz edildi. ACYÖ'den 11 puan altı alanlar grup I, 11 ve üzeri puan alanlar ise grup II olarak adlandırıldı. Hastaların demografik özellikleri ve tüm ölçüm sonuçları normal dağllıma uygunluk açısından Kolmogorov Smirnov testi ile değerlendirildi. Gruplar arası karşılaştırmalar Ki-Kare testi ile, sürekli değişkenlerin ortalamalarının karşılaştırılma$\mathrm{s} 1$ ise $\mathrm{t}$ testi kullanılarak değerlendirildi. Sonuçlar ortalama \pm standart sapma olarak belirtildi. İstatistiksel anlamlilik düzeyi $\mathrm{p}<0.05$ olarak alındı. Özellikler arasındaki ilişki pearson korelasyon analizi kullanılarak değerlendirildi ve r değeri $0-0.24$ zayıf, $0.25-0.49$ orta, $0.5-0.74$ güçlü, $0.75-1$ çok güçlü ilișki olarak kabul edildi.

\section{Bulgular}

Çalışmaya toplam 56 RRMS hastası alındı. Hastaların ortalama yaşı $35.07 \pm 8.72$ yıl $(21-46)$ idi. Has- taların 34'ü (\%60.7) kadın, 22'si (\%39.3) erkekti. Kadın cinsiyetin ortalama yaşı $35.14 \pm 8.38$ yıl, erkek cinsiyetin ortalama yaşı $34.94 \pm 9.42$ y1ldı. Her iki cinsiyet arasında ortalama yaş açısından istatistiksel anlamlı fark yoktu (p>0.05). Hastaların 15'i (\%26.8) bekar, 41'i (\%73.2) evliydi. Ortalama atak sayıs 3.51 \pm 2.18 ( $\mathrm{Min}=2$, Max=9), ortalama EDSS $2.35 \pm 1.53$ (0-4.5) idi. Kadın cinsiyetin ortalama EDSS'si $2.29 \pm 1.45$, erkek cinsiyetin ortalama EDSS'si $2.45 \pm 1.68$ idi. Her iki cinsiyet arasında ortalama EDSS açısından istatistiksel anlamlı fark yoktu ( $p>0.05)$. Ortalama hastalık süresi $6.14 \pm 3.14$ yıldı. Ortalama BDÖ 8. $6 \pm 3.04$ (0-12)'dü. Cinsiyetler arasında ortalama hastalık süresi açısından istatistiksel anlamlı farklılık yoktu ( $p>0.05)$. Hastalık süresi ile EDSS arasında istatistiksel olarak anlamlı bir ilişki vard $(\mathrm{p}<0.0001, \mathrm{r}=0.68)$. Ortalama eğitim yılı kadınlarda $4.17 \pm 3.01$ y1l, erkeklerde $3.73 \pm 3.32$ yıldı. Cinsiyetler arasında ortalama eğitim yılı açısından istatistiksel anlamlı farkl1lı yoktu ( $\mathrm{p}>0.05)$.

Kadın cinsiyette ortalama ACYÖ 16. 26 5 5.12, erkek cinsiyette ortalama ACYÖ $15.5 \pm 4.67$ idi. Her iki cinsiyet arasında ortalama ACYÖ açısından istatistiksel anlamlı fark yoktu ( $>0.05)$. Kadın hastaların 31'inde (\%91.2), erkek hastaların 19'unda (\%86.4) ACYÖ 11 ve üzerindeydi. Her iki cinsiyet grubunda da, ACYÖ puanları ile hastalık süresi ve EDSS arasında istatistiksel anlamlı ilişsi yoktu $(\mathrm{p}>0.05)$.

ACYÖ puanı 11 altı olan grup I ile 11 ve üzeri olan grup II arasında sosyodemografik özellikler açısından istatistiksel olarak anlamlı farkl111k yoktu ( $\mathrm{p}>0.05$ ) (Tablo I). Ayrıca iki grup arasında yaş, hastalık süresi, EDSS skoru ve eğitim yılı ortalamaları bakımından da istatistiksel anlamlı bir farkl111k yoktu ( $>0.05)$.

\section{Tartışma}

MS hastalarında çoğu kez cinsel işlev bozukluğu nedenini izole olarak belirlemek güç olsa da, cinsel sorunlar sık görülmektedir. Birçok çalışmada farklı sonuçlar rapor edilse de genel olarak kadınlarda seksüel ilgide azalma \%29-86, genital duyuda azalma \%43-62, orgazm kapasitesinde azalma \%24-58, vaginal kuruluk \%12-40, disparoni \%6-40 oranında; erkeklerde libidoda azalma $\% 37-86$, ereksiyon sorunları \%34-80, ejakülasyon sorunlar1 \%34-61 oranındadır (Borello ve ark., 2004; Schmidt ve ark., 2005). Demirkıran ve arkadaşları, değişik klinik alt gruplardan olan toplam $51 \mathrm{MS}$ hastasinda \%80.4 oranında cinsel işlev bozukluğu olduğunu ve en sık görülen disfonksiyonun da \%80.5 oranında libidoda azalma oldugunu göstermiştir (Demirkıran ve ark., 2006). MS'de olas1 cinsel işlev bozukluğunun özürlülük ve bilinen başka bir cinsel işlev bozukluğu sebebi olmadan varlığını ve oranını göstermeyi amaçlayan çalışmamızda cinsel işlev bozuklukarınn alt grubu bakılmamıştır. Çalışmamızda cinsel işlev bozukluklarının alt grubu belirlenmemiş olmasına rağmen cinsel bozukluk oranının genel olarak kadın hastalarda 
\%91.2, erkek hastalarda \%86.4 olduğu görüldü.

Yapılan çalışmalar cinsel işlev bozukluğu ile klinik seyir veya hastalık süresi arasında ilişki olmadığını; ancak cinsel işlev bozukluğunun mesane/barsak fonksiyonları, alt ekstremite duyu ve motor fonksiyonları, MR lezyon yükü, depresyon ve bilişsel sorunlar ile korelasyon gösterdiğini bildirmektedir (McCabe, 2002; Borello ve ark., 2004). Bizim hasta grubumuzda da cinsel işlevler ile hastalık süresi ve EDSS arasında istatistiksel anlamlı bir ilişki yoktu. Hastalarımızın tümünde klinik seyir relapsing remitting formdaydı. Hastalarımızın hiçbirinde ileri derecede otonom sistem bozukluğu, alt ekstremite fonksiyon bozukluğu ve bilinen psikiyatrik problem yoktu. Bu nedenle hastalarımızda \%90 düzeyinde görülen cinsel işlev bozukluğunun tüm bu faktörlerden bağımsız olarak hastalığın santral sinir sistemindeki etkilerine veya hastaların yaşadığı uyum problemlerine bağlı gelişebileceği düşünüldü.

Hastaların ortalama EDSS $2.35 \pm 1.53$ olup cinsel işlevleri etkileyebilecek ölçüde özürlülük yoktu. Ayrıca hastaların hiçbirinde cinsel işlev bozukluğuna neden olabilecek psikiyatrik bir problem veya ilaç kullanım öyküsü de yoktu. Çalışmamızda sadece RRMS grubunda olan ve ileri özürlülügü olmayan seçilmiş bir hasta grubunda olası cinsel fonksiyon bozukluğu araştırılmıştır. Hem MS'de sık görülmesi ve hem de cinsel işlev bozukluğunun önemli nedenlerinden biri olan depresyonun varllğı özellikle bakılmış ve depresyonu olanlar çalışmaya alınmamıştır. Çalışmamızda depresyon dişındaki psikososyal etmenleri araştırmak için kullandığımız her hangi bir ölçek olmamasına rağmen, çalışmaya alınan hastaların genel psikiyatrik değerlendirmelerinde herhangi bir psikiyatrik bozukluk yoktu. Cinsel işlev bozukluğuna neden olabilecek bilinen bir risk faktörü olmamasına rağmen, hastalarımızın çoğunda görülen cinsel işlev bozukluğu, hastalığın santral sinir sistemi üzerindeki etkileri sonrası gelişen nöral enformasyondaki etkilenme ile açıklanabileceği gibi hastaların yaşadığı psikososyal etmenlere bağlı da olabilir. Çalışmamızda psikososyal etmenleri araştırmak için kullandığımız her hangi bir ölçek olmamasına rağmen, MS hastalarında vücut işlevleri, beden imajı değişiklikleri, çekicilik, yeterlilik endişelerinin yanı sıra eşler arasında yeni rollere uyum sorunları yaşandı ğı bilinmektedir (Özkan, 1993; Schmidt ve ark., 2005). Bunlar da cinsel işlev bozukluğuna yol açabilecek etmenlerdir.

MS'de cinsel işlev bozukluğu oldukça sık karş1laşılan, ancak genellikle atlanan önemli bir sorundur. Çalışmamızda da cinsel işlev bozukluğu yapabilecek bilinen bir risk faktörü olmayan, seçilmiş RRMS hasta grubunda her iki cinsiyette de \%90'a varan cinsel işlev bozukluğu olduğu görüldü. Sağlık çalışanları zaman sınırlılığı, bilgieğitim eksikliği, cinsellik konusunda kişisel anksiyete nedeniyle MS hastalarıyla cinsel davranışlarını görüşmede zorluk yaşayabilir. Oysa sağlık çalışanları cinsel yaşam etkinliklerini hasta ile açıkça konuşmak için yeterli bilgiye sahip olmalı, cinsel sorununu açıklayamayan bireyin güçlüklerini anlayabilmeli, etkili bir eğitim ve danışmanlık hizmeti verebilmeli, cinsel sorunlarla başa çıkma yöntemleri konusunda hastaları cesaretlendirici ve yönlendirici rol üstlenebilmelidir. MS hastalarının ruhsal ve cinsel sorunlarının yaygınlığının bilinmesi ve tedavi edilmesi hastaların yaşam kalitesi açısından oldukça önemlidir.

Cinsel işlev bozukluğu çalışmamızda da görüldüğü gibi, MS hastalarında sıklıkla görülebilen bir semptomdur. Hastalarda ileri derecede özürlülük olmaksızın hastalığın her aşamasında görülebilmektedir. Bu kadar sık görülebilen bu semptomun klinik pratikte iyi sorgulanmas1 ve uygun şekilde tedavisinin planlanması, MS hastalarının yaşam kalitesini artırmak açısından büyük önem taşımaktadir.

\section{KAYNAKLAR}

Baral, I., Enderer M. Gök, S., Özkan, S., 1995. Konsültasyon liyezon psikiyatrisi yönünden psikiyatri dışı kliniklerde değerlendirilen deliryum olguları. Nöropsikiyatri Arşivi. 32, 32-36.

Beck, A. T., 1961. An Inventory for measuring depression. Arch. Gen. Psychiatry. 4, 561 -571.

Borello, F. D., Leng, W., O’Leary, M., 2004. Bladder and sexual function among women with multiple sclerosis. Mult. Scler. 10, 455- 461.

Brown, G. R., Haaser, R. C., 2005. Sexual Disorders: Textbook of Psychosomatic Medicine. 1. ed, Levenson JL eds. American Psychiatric Publishing, Washington, pp. 359-386.

Confavreux, C., Vukusic, S., Moreau, T., Adeleine, P., 2000. Relapses and progression of disability in multiple sclerosis. N. Engl. J. Med. 343, 1430-1438.

Costello, K., Haris, C., 2003. Differential diagnosis and management of fatigue in multiple sclerosis: considerations for the nurse. J. Neurosci. Nurs. 35, 139-148.

Demirkıran, M., Sarıca, Y., Uguz, S., et al., 2006. Multiple sclerosis patients with and without sexual dysfunction: are there any differeces?. Multiple Sclerosis. 12, 209-214.

Fraser, C., Mahoney, J., McGurl, J., 2008. Corraletes of sexual dysfunction in man and women eith multiple sclerosis. J. Neurosci. Nurs. 40, 312-317.

Gilroy, J., 2000 Basic neurology (3 rd ed). Mc Graw-Hill, New York, pp 199-223.

Kessler, T. M., Fowler, C. J., Panicker, J. N., 2009. Sexual Dysfunction in Multiple Sclerosis. Expert. Rev. Neurother. 9, 341-350. 
Kurtzke, J., 1983. Rating neurologic impairment in multiple sclerosis: An expanded disability status scale (EDSS). Neurology. 33, 1444-1452.

McCabe, M. P., 2002. Relationship functioning and sexuality among people with multiple sclerosis. J. Sex. Research. 4 , $302-309$.

McDonald, W. I., Compston, A., Edan, G., 2001. Recommended diagnostic criteria for multiple sclerosis: guidelines from the International panel on the diagnosis of multiple sclerosis. Ann. Neurol. 50, 121-127.

McGahuey, C. A., Gelenberg, A. J., Laukes, C. A., 2000. The Arizona Sexual Experience Scale (ASEX): reliability and validity. J. Sex Marital. Ther. 26, 25-40.

Miller, A. E., 2001. Clinical features. In: Cook SD, ed. Handbook of multiple sclerosis. 3rd ed. New York: Marcel Dekker. Pp. 231232.

Özkan, S., 1993. Konsültasyon-Liyezon Psikiyatrisi. İstanbul.

Paty, D. W., Noseworthy, J. H., Ebers, G. C., 1997. Diagnosis of multiple sclerosis. In: Pathy DW, Ebers GC, eds. Multiple sclerosis. Philadelphia: FA Davis. Pp. 48-134.

Schmidt, E. Z., Hoffmann, P., Niederwieser, G. K., 2005. Sexuality in multiple sclerosis. J. Neural. Transm. $112,1201-1211$.

Soykan, A., 2004. The reliability and validity of Arizona sexual experiences scale in Turkish ESRD patients undergoing hemodialysis. Int. J. Impot. Res. 16, 531- 534.

Tegin, B., 1980. Depresyonda Bilişsel Bozukluklar: Beck Modeline Göre Bir İnceleme. Doktora Tezi, Ankara, Hacettepe Üniversitesi. 